\title{
Kinerja Jalan di Kawasan Jl. Kolonel Abunjani Kota Jambi
}

\author{
${ }^{1}$ Elvira Handayani, ${ }^{2}$ Kiki Rizky Amalia, ${ }^{3}$ Ilkham Khamal \\ ${ }^{1,2}$ Dosen Fakultas Teknik Sipil Universitas Batanghari Jambi \\ ${ }^{3}$ Mahasiswa Teknik Sipil Universitas Batanghari Jambi \\ Email : Elvira handayani2@yahoo.co.id
}

\begin{abstract}
Abstrak
Sektor transportasi merupakan salah satu sektor yang sangat penting dalam mendukung aktivitas sehari-hari seperti kegiatan ekonomi, pendidikan, dan dalam kegiatan perkantoran serta kegiatan lainnya, pada suatu wilayah apabila populasinya mengalami pertumbuhan yang cukup pesat, maka secara linear terjadi pula peningkatan jumlah kendaraan. Salah satunya yan terjadi dijalan di Jl.Kolonel Abunjani, Kota Jambi. Tujuan penelitian ini adalah untuk memberikan solusi dari berbagai masalah seperti: kemacetan, kerusakan jalan, resiko kecelakaan serta polusi udara dengan mempertimbangkan besarnya pengaruh dari kendaraan berat terhadap kinerja ruas jalan serta keadaan disekitarnya, hasiln tingkat pelayananya seperti rekayasa lalu lintas.
\end{abstract}

Kata kunci: transportasi; jalan, lalu lintas

\section{PENDAHULUAN}

Jalan merupakan sarana transportasi darat yang sangat penting bagi masyarakat untuk berhubungan antara daerah yang satu ke daerah yang lain, selain itu juga untuk mempelancar kegiatan perekonomian, dan aktivitas sehari-hari masyarakat.

Kemacetan lalu lintas disebabkan oleh tidak seimbangnya antara peningkatan kepemilikan kendaraan dan pertumbuhan prasarana jalan yang tersedia serta kapasitas efektif ruas jalan yang ada lebih kecil dari kapasitas jalan yang direncanakan akibat adanya hambatan ditepi jalan. Hambatan ditepi jalan tersebut sering kali terkait dengan adanya aktivitas sosial dan ekonomi, yaitu adanya parkir dibadan jalan yang dikarenakan terdapat pertokoan yang tidak menyediakan tempat parkir, sarana angkutan umum yang menurunkan disembarang tempat serta lalu lalangnya orang untuk menyeberang yang menyebabkan kapasitas jalan mengalami penurunan.

\section{Landasan Teori}

Transportasi adalah memindahkan atau mengangkut sesuatu dari suatu tempat ketempat lain, seperti perpindahan barang atau penumpang dari satu lokasi kelokasi lainya. Dengan produk yang digerakan atau dipindahkan ke lokasi yang dibutuhkan atau yang diinginkan.

Transportasi dikatakan baik apabila perjalanan cukup cepat, tidak mengalami kemacetan, frekuensi pelayanan cukup, aman, bebas dari kecelakaan dan kondisi pelayanan yang aman dan nyaman. Untuk mencapai kondisi ideal seperti ini, sangat ditentukan oleh berbagai faktor yang menjadi komponen transportasi ini yaitu kondisi prasarana (jalan), sistem jaringan jalan, kondisi sarana (kendaraan) dan sikap mental pemakai fasilitas transportasi tersebut.

Perencanaan geometrik jalan adalah suatu perencanaan rute dari suatu jalan secara lengkap, beberapa komponen jalan yang dirancang berdasarkan kelengkapan data dasar, yang didapat dari hasil survey lapangan, kemudian dianalisis berdasarkan acuan persaratan yang berlaku (modul jalan raya 1,2012 ).

Selain itu, Perencanaan geometrik jalan dapat juga diartikan sebagai suatu bagian dari perencanaan konstruksi jalan dimana geometrik atau dimensi yang nyata dari suatu jalan beserta bagian-bagian disesuaikan dengan tuntutan serta sifat-sifat lalu lintasnya. Perencanaan tersebut disesuaikan dengan persyaratan parameter pengendara, kendaraan dan 
lalu lintas. Parameter tersebut merupakan penentu tingkat kenyamanan dan keamanan yang dihasilkan oleh suatu bentuk geometrik jalan ( Silvia Sukirman, 1999 ).

\section{Tingkat pelayanan $E$}

1. Arus lalu lintas rendah dari pada tingkat pelayanan D dengan volume lalu lintas mendekati kapasitas jalan dan kecepatan sangat rendah.

2. Kepadatan lalu lintas tinggi karena hambatan internal lalu lintas tinggi.

3. Pengemudi mulai merasakan kemacetan-kemacetan durasi pendek

\section{Tingkat pelayanan $C$}

1. Arus stabil tetapi kecepatan dan pergerakan kendaraan dikendalikanoleh volume lalu lintas yang lebih tinggi.

2. Kepadatan lalu lintas meningkat dan hambatan inetrnal meningkat.

3. Pengemudi memiliki keterbatsan untuk memilih kecepatan, pindah lajur atau mendahului

Tabel 1. Perhitungan kecepatan arus bebas

\begin{tabular}{ccccc}
\hline Fvo Km/jam & FVw & FFVsf & FFVcs & FV Km/jam \\
\hline 51 & 2,00 & 0,85 & 0,93 & 42 \\
\hline
\end{tabular}

Sumber : Hasil analisa,2019

\section{METODE}

Sebelum melakukan semua kegiatan pelaksanaan penelitian,maka perlu dilakukan pekerjaan persiapan.Adapun hal-halyang perlu dipersiapkan antara lain:

1. Mencaridan mengumpulkan informasi yang berkaitan tentang topik penelitian sebanyak mungkin untuk memudahkan pekerjaan analisis selanjutnya.

2. Mengumpulkan literature pendukung yang akan digunakan dalam proses analisis baik secara manual maupun menggunakan sistem komputerisasi.

3. Mengumpulkan bahan-bahan alternatif dari penelitian-penelitian sebelumnya yang relevan dengan penelitian yang dilakukan sebagai bahan pembanding terhadap penelitian yang akan dilakukan.

\section{Pengumpulan Data}

Survey Pendahuluan

Survey ini bertujuan untuk menentukan titik survey dan jumlah sampel yang akan dilakukan dalam penelitian ini.Penentuan titik survey dilakukan dikedua segmen ruasJl.kolonel Abunjani, yaitu Dari STA 300 Sampai ke STA 850

\section{Survey Lapangan}

Dengan suveyor : 6 orang, yang dimasing-masing titik 2 orang surveyor. Pada Survey ini dibutuh kan adalah data primer.

1. Data Primer

Adapun data primeryang digunakan dalam penelitian iniadalah berupa:

a. Kondisi Geometrik Jalan

Dalam penelitian ini, data kondisi geometric jalan menjadi hal utama dalam menentukan tingkat kemacetan yang terjadi pada ruas jalan yang akan diteliti.

b. Volume Kendaraan

Volume Kendaraan yang akan diteliti pada penelitian ini adalah jumlah kendaraan yang melewati titik pengamatan yang ditentukan yaitu STA 300 Sampai STA 850. Pendataan dilakukan menggunakan alat manual seperti ,pena , Stopwatch tabel kelas kendaraan

c. Kecepatan Kendaraan

2. Data Sekunder 
a. Peta lokasi Penelitian

b. jumlah penduduk Kota Jambi

\section{HASIL}

\section{Hasil Pengamatan Kondisi Ruas Jalan}

Ruas Jalan Kolonel Abunjani yang membentang berdasarkan hasil pengukuran geometrik ruas jalan pada lokasi studi yang meliputi panjang jalan, lebar perkerasan jalan, lebar jalur lalulintas, lebar dan jumlah lajur lalulintas dan lebar saluran drainase, maka diperoleh hasil sebagai berikut :

Tabel 2. Geometrik ruas Jalan Kolonel Abunjani

\begin{tabular}{ccccc}
\hline \multirow{2}{*}{ Nama Jalan } & \multicolumn{2}{c}{$\begin{array}{c}\text { Panjang Jalan yang } \\
\text { ditinjau (Mtr) }\end{array}$} & \multicolumn{3}{c}{ Lebar Bagian Jalan (Meter) } \\
\cline { 3 - 5 } & Lajur Lalulintas & Median & Drainase \\
\hline Jalan Kolonel Abunjani & 550 & $4 \times 3.75$ & 1.00 & $2 \times 1.00$ \\
\hline Sumber :Hasil Pengukuran,2019 & & &
\end{tabular}

Potongan melintang dan tampak atas ruas Jalan Kolonel Abunjani Kota Jambi berdasarkan hasil pengukuran yang telah dilaksanakan, dapat dijelaskan sebagaimana gambar berikut:
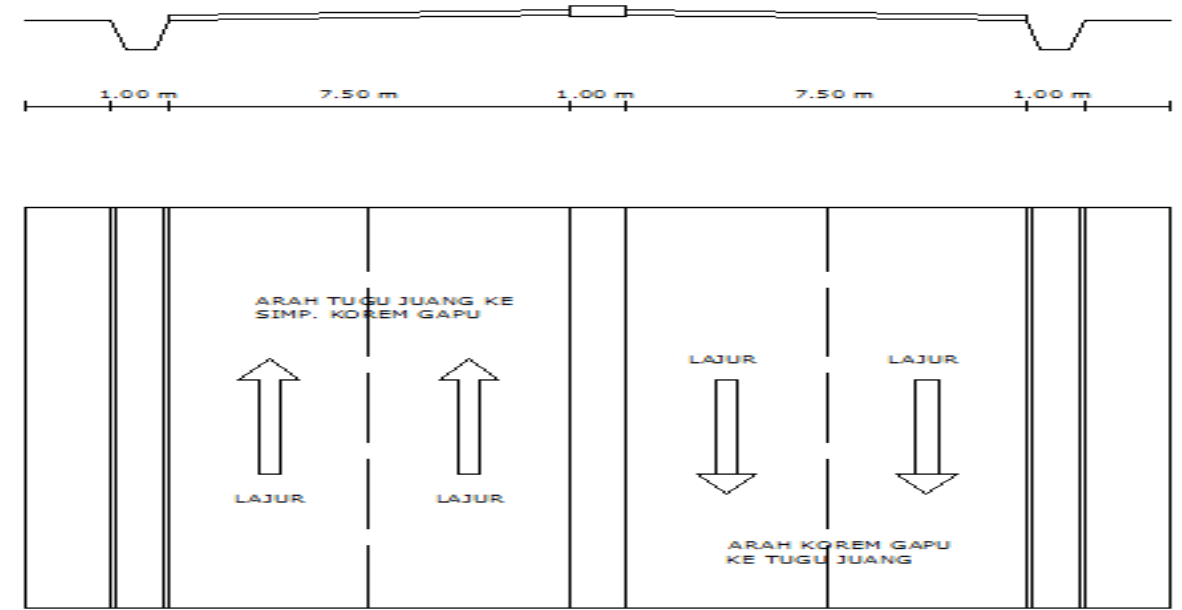

Sumber : Hasil pengukuran di Lapangan, 2019

Gambar 1 Potongan Melintang Jalan Kolonel Abunjani

\section{Volume Lalulintas}

Berdasarkan hasil survey yang telah dilaksanakan pada 3 (tiga) hari maka diambilah hari terpadat untuk volume lalulintas pada hari Jum'at pada tanggal 15 Februari 2019 selama 6 jam, yang terdiri dari jam sibuk pagi pada pukul 08.00 - 10.00 WIB atau selama 2 (dua) jam, jam sibuk siang hari pada pukul $11.00-14.00$ WIB atau selama 3 (tiga) jam, kemudian jam sibuk sore hari pada pukul 16.00 - $17.00 \mathrm{WIB}$, atau selama 1 (satu) jam, dengan perhitungan setiap jenis atau kelompok kendaraan secara manual dan setelah dilakukan analisa serta perhitungan data hasil survey, maka didapat volume lalulintas untuk ruas Jalan Kolonel Abunjani Yang dibagi untuk setiap arah dan waktu pengamatan untuk setiap kelompok kendaraan adalah sebagaimana tabel yag tersedia berikut ini.

Berdasarkan volume lalulintas hasil survey yang dihitung dalam satuan kendaraan per jam, selanjutnya ditentukan nilai faktor ekivalen mobil penumpang (faktor emp) menurut ketentuan dalam MKJI, 1997 yaitu sebagai berikut :
1. Sepeda Motor
$\mathrm{emp}=0,4$
2. Kendaraan Ringan (KR)
$\mathrm{emp}=1,0$ 


\section{Kendaraan Berat $(\mathrm{KB}) \quad \mathrm{emp}=1,3$}

Selanjutnya berdasarkan volume lalulintas dalam satuan kendaraan per jam tersebut, dilakukan perhitungan dengan mempergunakan faktor emp untuk mendapatkan volume lalulintas dalam satuan smp/jam. Perhitungan volume lalulintas dari satuan kendaraan/jam menjadi satuan smp/jam dapat dilakukan dengan cara mengalikan volume hasil survey dengan faktor emp, sebagai mana contoh perhitungan dibawah ini yaitu untuk periode jam survey pada pukul 08.00-09.00 WIB, diperoleh hasil sebagai berikut :

Tabel 3. Jumlah Smp/jam

\begin{tabular}{llcc}
\hline NO & Kendaraan & Jumlahkend x emp & Hasil Jumlah Smp/Jam \\
\hline 1 & Sepeda Motor & $1924 \times 0,4$ & 770 \\
2 & KendaraanRingan & $518 \times 1,0$ & 518 \\
3 & Kendaraan Berat & $7 \times 1,3$ & 9,1 \\
& Jumlah & 2449 & 1297 \\
\hline
\end{tabular}

Sumber :Hasil Penelitian,2019

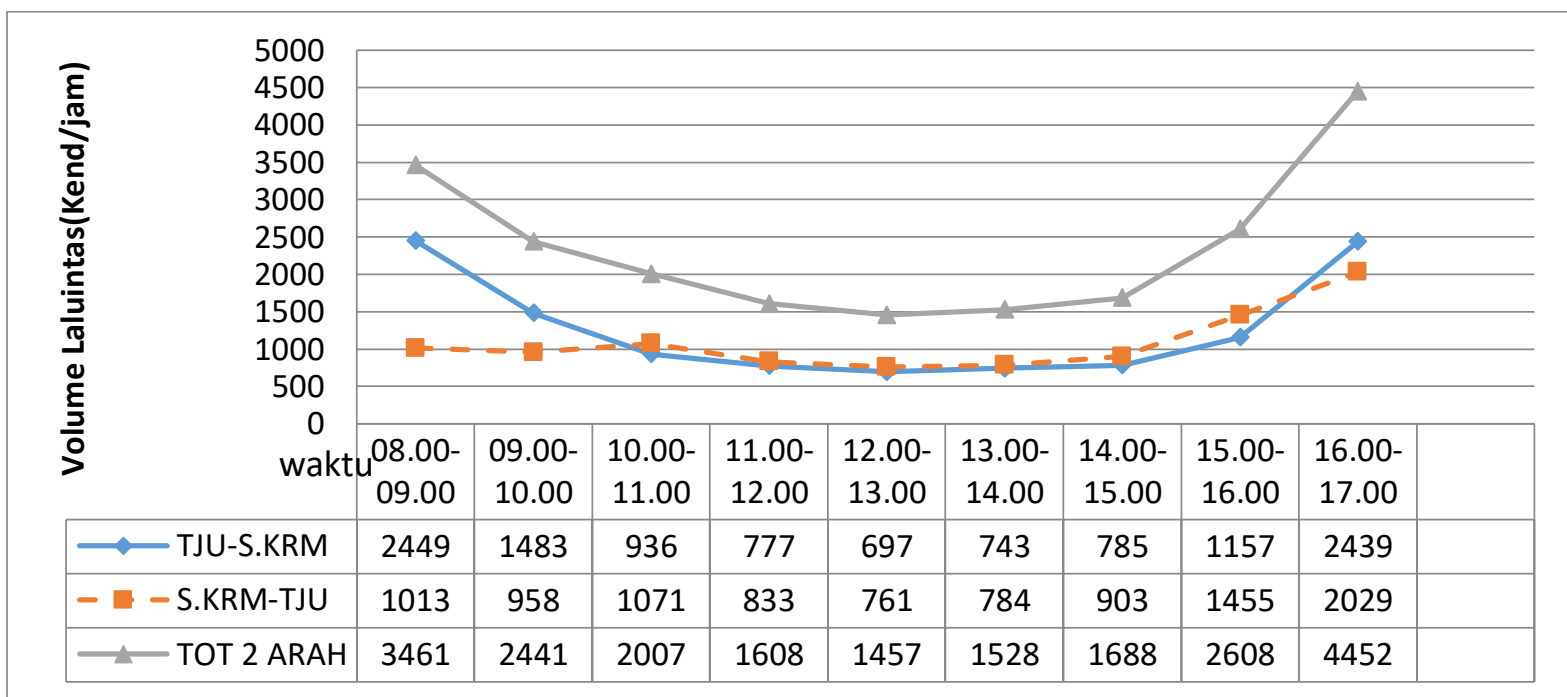

Sumber :Hasil Penelitian,2019

Gambar.2 Grafik fluktuasi arus lalulintas dalam kend/jam

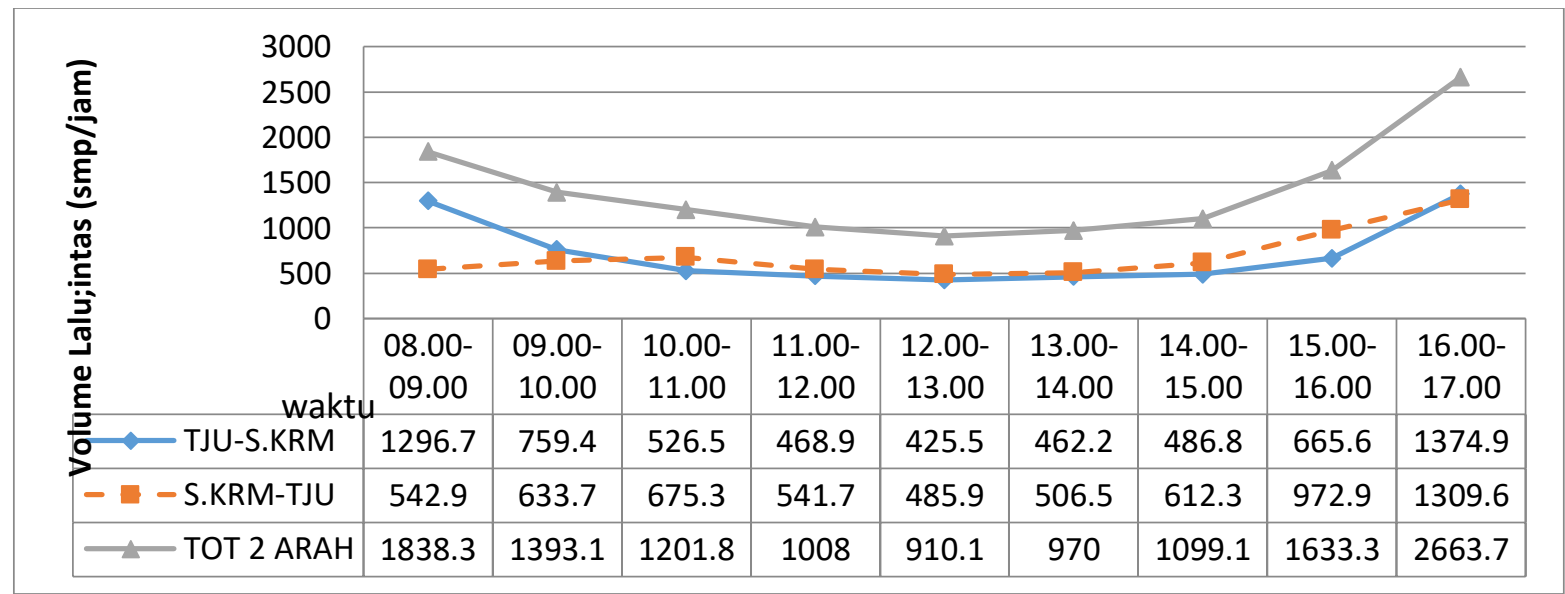

Sumber :Hasil Penelitian,2019

Gambar. 3 Grafik fluktuasi arus lalulintas dalam smp/jam

Keterangan :
TJU
: Tugu Juang
S.KRM
: Simp. Korem Garuda Putih 


\section{Kecepatan Arus Lalulintas}

Berdasarkan hasil pengukuran waktu tempuh untuk segmen panjang jalan 100 meter selama priode jam puncak pagi siang dan sore hari, yang kemudian dilakukan perhitungan dengan menggunakan analisis Space Mean Speed atau kecepatan rata-rata ruang (Us), diperoleh sebagaimana berikut :

Tabel 4. Kecepatan rata-rata ruang (Us) arus lalulintas diruas Jalan Kolonel Abunjani pada beberapa jam puncak

\begin{tabular}{clccc}
\hline & \multicolumn{1}{c}{ Arah Lalulintas } & \multicolumn{2}{c}{ Kecepatan Rata-rata Ruang (Us) (Km/jam) } \\
Ruas Jalan & Pagi & Siang & Sore \\
\hline \multirow{3}{*}{ Jalan Kolonel Abunjani } & Minimum & & & \\
& Maksimumn & 25 & 30 & 22 \\
& Korem Gapu - Tugu Juang & 30 & 35 & 25 \\
& Minimum & & & 22 \\
& Maksimum & 25 & 35 & 25 \\
\hline
\end{tabular}

Sumber : Hasil Analisa Data, 2019

Dengan hasil penelitian tabel diatas dengan adanya kendaraan yang parker pada badan jalan mengakibatkan kecepatan rata-rata pada kecepatan kendaraan pada jam puncak pagi hari dapat mencapai $25 \mathrm{~s} / \mathrm{d} 30 \mathrm{~km} / \mathrm{jam}$, dan pada jam puncak siang hari dapat mencapai $35 \mathrm{~s} / \mathrm{d}$ $40 \mathrm{~km} / \mathrm{jam}$, dan pada jam puncak sore hari dapat mencapai kecepatan $22 \mathrm{~s} / \mathrm{d} 25 \mathrm{~km} / \mathrm{jam}$.

\section{Kinerja Ruas Jalan Pada Kondisi Saat Ini}

Kinerja ruas jalan dihitung berdasarkan metode Manual Kapasitas Jalan Indonesia MKJI, 1997 dimana parameter yang akan ditinjau adalah diantaranya adalah perbandingan (rasio) volume terhadap kapasitas (Q/C rasio)

Kapasitas ruas jalan dihitung dengan persamaan :

\section{C=CoxFCw x FCsp x FCsf x FCes (smp/jam)}

Dimana :

$\mathrm{C}=$ Kapasitas dalam smp/jam

Co $\quad=$ Kapasitas dasar dalam smp/jam

$\mathrm{FCw}=$ Faktor penyesuaian lebar jalur LL

FCsp = Faktor penyesuaian pemisah arah

FCsf = Faktor penyesuaian hambatan samping

FCcs $=$ Faktor penyesuaian ukuran kota

Perhitungan kapasitas untuk ruas Jalan Kolonel Abunjani sebagai tabel berikut ini

Tabel 5. Perhitungan Kapasitas ruas jalan

\begin{tabular}{cccccccc}
\hline Co Smp/Jam & FCw & FCsp & FCsf & FCcs & C Smp/jam & Jumlah Lajur Efektif & C Total smp/jam \\
\hline 1650 & 1,04 & 1,00 & 0,92 & 0,90 & 1421 & 2 & 2482 \\
\hline
\end{tabular}

Sumber : Hasil penelitian, 2019

Dari tabel diatas diketahui bahwa kapasitas efektif untuk ruas Jalan Kolonel Abunjani adalah 2732 smp/jam, dengan demikian nilai Q/C rasio untuk lalulintas 2 (dua) arah dapat dihitung sebagai berikut :

1. Periode jam puncak pagi $\mathrm{Q} / \mathrm{C}=1838,3 / 1421=1,289$

2. Periode jam puncak siang $\mathrm{Q} / \mathrm{C}=1008 / 1421=0,709$

3. Periode jam puncak sore $\mathrm{Q} / \mathrm{C}=2663,7 / 1421=1,875$

Perameter selanjutnya yang harus dihitung untuk menentukan kinerja ruas jalan adalah kecepatan arus bebas, yaitu : 


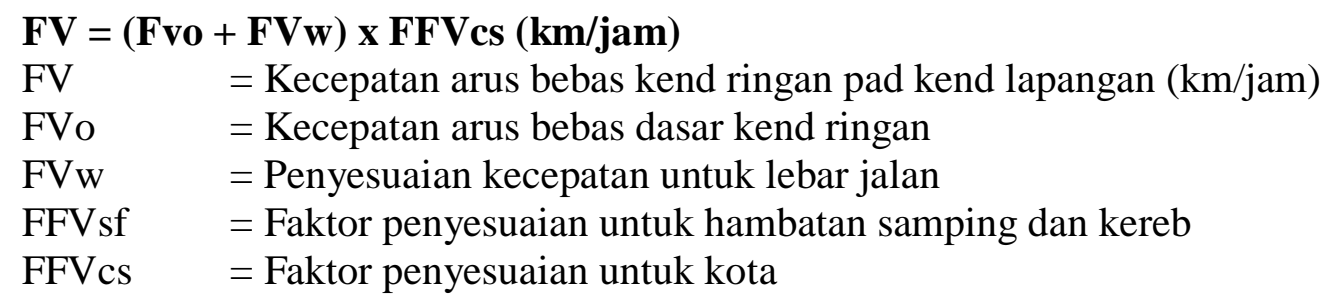

Dari hasil perhitungan tersebut di atas diperoleh kecepatan arus bebas (FV) pada ruas Jalan Kolonel Abunjani adalah $42 \mathrm{~km} / \mathrm{jam}$, dan kecepatan rata-rata ruang pada setiap jam puncak adalah :

1. Periode jam puncak pagi Us $=25-30 \mathrm{~km} / \mathrm{jam}$

2. Periode jam puncak siang Us $=35-40 \mathrm{~km} / \mathrm{jam}$

3. Periode jam puncak sore $\mathrm{Us}=22-25 \mathrm{~km} / \mathrm{jam}$

Berdasarkan hasil analisa $\mathrm{Q} / \mathrm{C}$ rasio, kepadatan lalulintas, kecepatan rata-rata dan kecepatan arus bebas maka dapat ditentukan kinerja atau tingkat pelayanan jalan untuk Jalan Kolonel Abunjani saat ini yaitu untuk kondisi pagi dan sore hari adalah "E" serta kondisi siang dan siang hari adalah "C".

\section{SIMPULAN}

1. Bedasarkan hasil survey dan analisa data dapat diketahui bahwa komposisi arus lalulintas Jalan Kolonel AbunJani dimana kendaraan yang paling dominan adalah sepeda motor (SM) dan kendaraan ringan (KR), dimana perbandingan komposisi ketiga kelompok kendaraan tersebut, rata-rata presentasenya adalah sebagai berikut,Dari hasil perhitungan dan analisa didapat presentase komposisi arus lalu lintas jalan Kolonel Abunjani sebagai berikut :
1. Sepeda Motor (SM)
$=67,06 \%$
2. Kendaraan Ringan (KR)
$=32,54 \%$
3. Kendaraan Berat
$=0,40 \%$

2. Kecepatan rata-rata kendaraan pada jam puncak :

\begin{tabular}{ccc}
\multicolumn{2}{c}{ Kecepatan Rata-rata ruang (Km/jam) } \\
Pagi & Siang & Sore \\
25 s/d 30 & $30 \mathrm{~s} / \mathrm{d} \mathrm{35}$ & $22 \mathrm{~s} / \mathrm{d} 25$ \\
$25 \mathrm{~s} / \mathrm{d} 30$ & $35 \mathrm{~s} / \mathrm{d} 40$ & $22 \mathrm{~s} / \mathrm{d} 25$
\end{tabular}

3. Berdasarkan hasil analisa $\mathrm{Q} / \mathrm{C}$ rasio, kepadatan lalulintas, kecepatan rata-rata dan kecepatan arus bebas maka dapat ditentukan kinerja atau tingkat pelayanan jalan untuk Jalan Kolonel Abunjani saat ini yaitu untuk kondisi pagi dan sore hari adalah "E" serta kondisi siang dan siang hari adalah "C".

\section{DAFTAR PUSTAKA}

Adisasmita, S. A. (2014). Transportasi Komprehensif dan Multi Moda. Yogyakarta : Graha Ilmu.

Adsasmita, R. (2015). Analisis Kebutuhan Transportasi. Yogyakarta:

GRAHA ILMU.

BINKOT. (1997). Manual Kapasitas Jalan Indonesia (MKJI). Bandung:

DIRJEN BINA MARGA.

Khisty, C., \& Lall, B. K. (2003). Dasar-dasar Rekayasa Transportasi.Jakarta: Erlangga.

Novalia, C. (2015). Analisa dan Solusi Kemacetan Lalu Lintas Diruas Jalan Kota..Bandar Lampung: Universitas Lampung.

Rahayu, T. (2006). Kajian Kemacetan Lalu Lintas Pada Kawasan Daerah Medan-Binjai. Medan: Universitas Sumatra Utara.

Sukirman, S. (1999). Dasar-dasar Perencanaan Geometrik Jalan. Bandung: Nova. 